\title{
RECOVERY FROM THE PERMIAN-TRIASSIC MASS EXTINCTION: DID ANOXIA PLAY A ROLE IN THE DELAYED MESOZOIC RADIATION?
}

WOODS, Adam D., and BOTTJER, David J., Department of Earth Sciences, University of Southern California, Los Angeles, CA 90089-0740, U.S.A.

rovery from mass extinctions generally occurs relatively quickly, ification occurring over time scales on the order of one to two

The recovery following the Permian-Triassic mass extinction

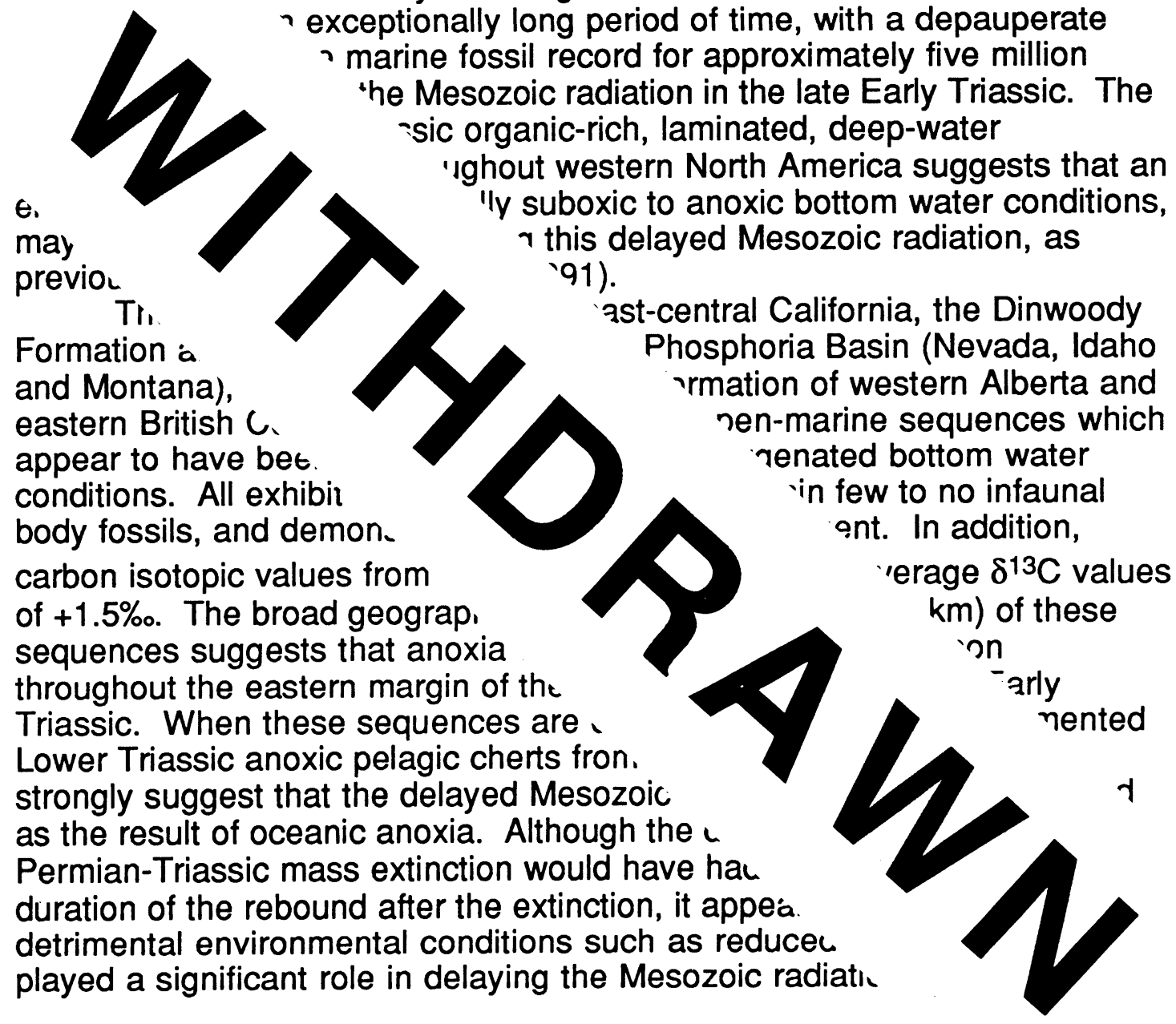

Hallam, A. 1991. Why was there a delayed radiation after the extinctions? Historical Biology, 5: 257-262.

Isozaki, Y. 1994. Superanoxia across the Permo-Triassic boundary: , srd in accreted deep-sea pelagic chert in Japan, p. 805-812. In A. F. Embry, B. Beauchamp and D. J. Glass (eds.), Pangea: Global Environments and Resources. Canadian Society of Petroleum Geologists, Calgary, Alberta, Canada. 